\title{
THE TEACHING OF PHYSICS.
}

\author{
By H. N. CH̊uTe, \\ High School, Ann Arbor, Mich. \\ [CONTINUED FROM THE APRIL NUMBER.]
}

To-day the pendulum is swinging the wrong way and it may be some time before it begins to return. In the meantime, it will be necessary for the physics instructor to spend much time in teaching arithmetic, not to mention penmanship, English, and housekeeping; occasionally he may find an opportunity to do a little work in physics.

I believe that most boys and girls, too, would enjoy the study of physics were it not for such difficulties as I have described, all of which grow out of their inadequate preparation for such a study. They are charmed by its novelties and enchanted by the beauties revealed. But before they have gone far into the subject, they come to a gate, with written above it in the language of Plato of old:- "Let none but geometricians enter here." Should they venture to pass within its portals, they find themselves in an atmosphere of mathematics, the forms of expression, many of the ideas are the children of mathematics. It was this fact that prompted Kepler to exclaim that, "the laws of Nature are but the mathematical thoughts of God."

I presume that the question now uppermost in mind is, "What can the teacher of physics do in the face of such difficulties?" Perhaps not very much, but I believe that he can help matters a little, notwithstanding the fact that habits of thought and methods of work are largely formed on the part of the student and in many cases ossified before he reaches physics.

Orie of the most general weaknesses to be found in pupils is in their almost utter helplessness in the face of a new problem. Here is a problem differing from the last one solved; it may be in mere phraseology, and he is hors de combat. Never with him does the thing asked have any connection in his thought with the solution. Every problem hitherto solved has been an effort of memory or a game of chance. He added, he divided, he subtracted, and looked for the answer. If obtained, all was well; if not, he tried another combination. Problem solving to him is puzzle solving, it is a jugglery with figures; it is a trying of all 
the combinations, a method of exhaustions. If you doubt this description, try the following on your class and watch the results:-A force of ten dynes acts on a mass of nine grammes and moves it eight centimetres. How much work is done? If I am not greatly mistaken the solution given will involve every quantity mentioned in the problem, regardless of what was called for.

We all admit that a change is very desirable. But how may it be brought about? You may establish mathematical laboratories, with blocks, rulers, and protractors galore; it matters not what concrete methods you adopt, problem solving will ever be the bug-bear of the school-boy until you make it more than has yet been done a question of sentence analysis, a study into the meaning of the words used. My contention is that the solution of every problem is to be found in the problem itself; that in asking for a certain thing to be found, a correct interpretation of the thing asked for, tells how to get it. Considerable experience in teaching both mathematics and physics have convinced me that no true progress can be made along any other road.

I have an impression that students are rarely taught in accordance with this precept; and my observation is, furthermore, that problem. work especially in algebra, is very largely ignored and instead the pupil is drilled from day to day on cut and dried equations and the reduction of complex expressions, and has little or no opportunity given him to learn how equations are written out of problems. And so the teacher has a severe task before him of training his pupils in the art of problem solving, in the method of attack. You will find that many will be attracted to your work by this novelty and you will save to your classes all that are probably worth saving.

Another perplexing problem to the instructor is the management of the recitation. Shall it be topical or catechetical? Why not both, neither exclusively? It would seem wise at times, quite frequently in fact, to have the student take up a topic and reproduce the thought or disctussion, the merit of the performance varying inversely as the amount of prompting required. $\mathrm{He}$ should also be able, and often be required, to answer questions bearing on any part or feature of the subject under consideration. The answer, it should be insisted, should fully meet the question asked, be it a definition or the underlying principle in any experiment, discussion or process, all to be presented in good English 
form, for this after all, is the most satisfactory evidence of acquired power.

And why have the questioning all on one side? The student that asks no questions is usually one that does no thinking. Many times some of the most helpful points are brought to the front through some question asked by a thoughtful student.

In these days we hear a great deal about the Laboratory Method. Sometimes I think that the teaching world has gone daft on this subject, for have they not tried to apply this method to the teaching of every known subject from cube root to Caesar. There are those who maintain that in science instruction this method should be used exclusively, that the pupil should "read Nature only in the light of experiment," a very catchy injunction, to be placed by the side of that other much abused pedagogical saying "Learn to do by doing." Our heuristic friends tell us that all information should reach the student through experiments performed by himself, that on entering upon his work he should be practically in the same state as regards scientific knowledge as the original performers of the experiment. "These original discoverers-the Newtons, Daltons, Cavendishes, and Blacks-says a writer in the School World, were ranked amongst the foremost intellects of their age, and this is a position that we can hardly expect the average school boy to occupy. The result is that the pupil is considerably in the dark as to the argument of his experiment, and in the majority of cases remains so. The heuristic method makes too little allowance for the naturally illogical nature of the average boy." Many of the fundamental facts of science, to develop experimentally, require the highest type of mechanical skill, most accurately constructed apparatus, and observational powers trained to the greatest acuteness. Then why have a laboratory associated with the teaching of physics? What is its mission? Certainly not discovery, neither is it verification, for the establishment of principles and laws is clearly beyond the skill of the novice, when men of genitus ofttimes labor hard and long to bring things to pass. Prof. Woodhull points out one of its uses in that "the student gets a realizing sense of things by coming in contact with them." And then the training it gives is not surpassed by that in any other line of work. It offers unparallelled opportunities to cultivate the observational powers. How few people use their eyes as they go through this world and still fewer see things just as they are. Ask your class 
to tell you which stroke of the letter $\mathrm{V}$ is shaded, the direction of the inclined bar in $\mathrm{N}$, and which way $\mathrm{S}$ curves, and it may surprise you to find what a large number are wrong. Appoint two students, without any laboratory training, to take independently the reading of a barometer at a given time and the difference in the reports is ofttimes considerable. Furnish a boy with dividers and scale and set him the task of measuring the length of a straight line that you have drawn on a sheet of paper, and it is wonderful how that line seemingly expanded and contracted during the progress of the work, and all because he had not the ability to see when one point was exactly on another, neither did he possess any ideas as to how he might assure himself when he had so placed them. Did you ever have a girl try to light the vertical rod of the iron ring-stand for a Bunsen burner, nearly twisting off the screw that clamped the ring in her frantic endeavors to turn on the gas? I have, more than once. Did you ever know a college president whose knowledge of Greek, Logic and Theology was unquestioned and yet he could not light the kerosene lamp on his study table. I knew one, and as you might expect he was no advocate of laboratory methods in education, and opposed to the bitter end the able teacher of physics in that college who was trying to inaugurate modern methods in his work and finally ousted him from his position. This man had seen a lamp lighted thousands of times, and yet there was a sense in which he had never seen it lighted. The ability to see things correctly is not a gift, it is an acquirement obtained through proper training, and it is in this direction that the physical laboratory renders most valuable service to those that work therein, The training to exactness and carefulness is another of its most important fruits. "All exact knowledge, says Maxwell, is founded" on the comparison of one quantity with another." Knowledge that is not exact has but little value and frequently is a detriment to the possessor. Let a student undertake to find the valueof " $\mathrm{g}$," and he soon discovers that he must measure the length of his pendulum within a millimetre to secure a result of any merit. And so all through the properly managed laboratory course, he has impressed upon him at every turn that if he cannot see accurately, manipulate carefully, and adjust with precision, there is nothing in store for him but failure, as there is "no apparatus of such cunning that it will not permit itself to be set: wrong or to be read wrong, and of such vigor of constitution 
that it will not mind being knocked off the table occasionally." $\mathrm{He}$ meets here with the highest type of manual training. $\mathrm{He}$ finds as he enters upon an experiment there is something for him to do that demands his closest attention. Here is a careful adjustment of the position of a scale and success hangs upon a hair's breadth deviation; a pressure to be measured by the sense of touch and failure is the penalty if his fingers give him no sense of magnitude; a group of apparatus to be formed and joined so that all parts work in perfect concert, if anything comes of his manipulations. He must adjust to hundredths of a millimetre, he must see to the tenth of a degree, he must weigh to the thousandths of a gramme, he must maintain a constant pressure on the contact key or his galvanometer needle will never rest; he must assemble the apparatus so that every part is easily accessible and every necessary adjustment is possible without upsetting everything in sight. "The habit of intelligent care, has been declared by some one, to be one of the most important objects to be attained in an education." Dr. J. O. Reed very forcibly expressed my point, when he said:--"The student who has learned to handle a spherometer or a vernier caliper properly, who can measure the focal length of a lens without dropping it upon the floor, who can adjust and operate a balance or a spectroscope without tearing either of them to pieces, in short, who can take up and use any piece of apparatus in the laboratory intelligently, and when done replace it where it belongs in as good condition as he found it, has made an acquisition for life."

In the system and order demanded in the laboratory we have a type of training furnished as thoroughly no where else. It is a place for work, neat and orderly work. One of its regulations should be "a place for everything and everything in its place." That teacher who permits a student to keep his table looking as if a cyclone had just swept across it, or closes his work for the day leaving everything in a turmoil, has certainly missed his calling. His place is in the junk-shop, where dirt and chaos may reign supreme, and no one be injured thereby.

I have already referred to the student's difficulty with language, his inability to arrive at the full meaning of a sentence. It is in the laboratory that he will find by sad experience how serious a matter this is. Directions not followed frequently bring disaster, and the bill for broken apparatus startles him. How few there are who are able to follow out to the letter a set of printed in- 
structions, I care not what the subject, and yet how often it is true that success can come solely by being able to do this.

It is in the laboratory the pupil learns the nature of experimental evidence. In the class-room as well as from the textbook he learns that a body submerged in water is buoyed up by a force equal to the weight of the water displaced. In the laboratory he soon finds out that exercising all the care of which he is capable he is unable to realize exactly this fact; but he notices that his measurements are marred by errors and that by increased care, which he comes to know how to exercise through experience gained by repetition, he approaches nearer and nearer a realization of the principle as stated, leading him to believe that if he could observe with still greater accuracy, and had at his command apparatus entirely divested of mechanical depravity, he could obtain results in perfect harmony with the principle of Archimedes.

The independence of thought and the consciousness of power that the laboratory begets are results of incalculable value. Mere head knowledge, or learning, does a man but little good. It is the habit of mind, the training in method and the cultivation of all his powers that determine his character and fix his worth. I sometimes doubt whether the primary aim of laboratory work in physics in our schools should be "scientific habits of thought about physical phenomena," so much as systematic habits of bringing things to pass. That physics cannot be taught without a laboratory is a very doubtful proposition, that it can be taught as well and with as much benefit to the pupil without it is certainly not true. In my judgment, the most effective teaching can be done by a judicious combination of methods. The text-book is needed to place before the student concise and accurate statements of the important facts and principles and furnish him language in which to express his ideas; the lecture and demonstration are needed to explain and illustrates laws which students cannot do for themselves from lack of time, or skill, or both; the laboratory is essential to make knowledge real and vivid in the student's mind and acquaint him with the method by which physics grows; and the recitation or quiz is indispensable for fixing facts, for ascertaining with what clearness the principles are understood and as a prod to those disposed to lag or shirk.

The proper apportioning of time between these different phases of the work is a difficult matter to determine, and one in which 
there is danger of going to extremes. Some place too much stress on the laboratory and too little on the quiz, others go to the opposite extreme, and the laboratory is one only in name, being an injury to the pupil in many ways. If there was unlimited time for physics there would be less difficulty in the matter. We must remember that the pupil has other subjects that demand a fair share of his time. It might be of interest to some to know the practice of the school with which $I$ stand connected. The week's work in physics comprises four class periods, each of one hour in length, one laboratory period of three hours' length and a laboratory report. Of the class periods, one is either a review of the class work, a quiz on the laboratory work, or a combined quiz on the two. A few years ago there were rumors among the teachers in our school that physics was demanding more time than was accorded to other subjects. The superintendent made a thorough investigation of the matter at the time and found that the charge was not based on fact, that there were at least five subjects paralleling physics in the various courses that were given more time by the pupil than was accorded to physics.

The length of the recitation period is another important question, and I am constrained to say that, in many schools, in my opinion, it is entirely too short. Experiments are great time consumers, many of them cannot be hastened. It is very necessary that every feature of an experiment be fully emphasized and the principles made clear, and whether clear or not determined by a few well directed questions. Experiments should be enforced by live illustrations brought in from the world of activity, to the end that the pupil may see wherein these principles have useful applications.

And finally, there is as much in the man as in the method or arrangement of work. "Physics, as Dr. Hall has said, is at the best, hard for most minds, young or old; and if the teacher is blessed with the gift, or can by pains acquire the power, of presenting his subject in an attractive way, of making his teaching artistic in form as well as sound in substance, he will win not only the respect of his pupils, but what is perhaps to both sides more stimulating, their admiration." 